Revised Paper submitted to

Industrial Marketing Management

Special Issue

Business-to-Business Service Networks

Edited by

Stephan C. Henneberg, Peter Naudé and Thorsten Gruber, Manchester Business School, UK

Submission February 2011

$1^{\text {st }}$ Revised Submission January 2012

$2^{\text {nd }}$ Revised Submission June 2012

SERVICE AND VALUE IN THE INTERACTIVE BUSINESS LANDSCAPE DAVID FORD AND STEFANOS MOUZAS

\author{
David Ford \\ Euromed - Management \\ Marseille, France \\ David.Ford@euromed-management.com \\ Stefanos Mouzas \\ Lancaster University \\ Lancaster La1 4yw \\ S.mouzas@lancaster.ac.uk
}




\title{
SERVICE AND VALUE IN THE INTERACTIVE BUSINESS LANDSCAPE
}

\begin{abstract}
This paper develops the concepts of service and value within an interactive business landscape. The paper builds on the IMP Group's general conceptualisation of the business process as one of substantive interaction between activities, resources and the actors associated with them (Håkansson et al., 2010). The paper grounds the conceptual discussion in a typical case study of the business process. The paper then analyses the case study using the IMP conceptualisation, contrasting this with the conventional Marketing Management Framework and SDL approach. This analysis leads to the development of a framework for service and value creation as an interactive process of multiple, reciprocal and sequential problem-coping with effects on a number of levels. The paper applies the framework for service and value creation to the analysis of a more detailed case study. Finally, the paper draws a number of conclusions about the nature of service and value in the business landscape for researchers and practitioners.
\end{abstract}

Keywords: interaction; service; value; networks. 


\section{INTRODUCTION}

The aim of this paper is to develop and refine the use of the concepts of service and value within analysis of the business process. The paper builds on the IMP Group's general conceptualisation of the business process as one of substantive interaction between activities, resources and the actors associated with them (Håkansson et al., 2010). The recent writing about the nature of service and value within the Service Dominant Logic (SDL) theme has been largely conceptual in orientation (e.g. Vargo and Lusch, 2004, 2006, 2008, 2011). To counter this, we start the paper by grounding our own conceptual discussion in a simple but rather typical case study of the business process. We analyse the case study using the IMP conceptualisation, contrasting this with the conventional Marketing Management Framework and SDL approach. This analysis leads to the development of a framework for service and value creation as an interactive process of multiple, reciprocal and sequential problem-coping with effects on a number of levels. We then attempt to apply this framework to the analysis of a more detailed case study. Finally, the paper draws a number of conclusions about the nature of service and value in the business landscape for researchers and practitioners.

\section{A CASE STUDY OF THE BUSINESS PROCESS: PRE-PREPARED READY-}

\section{MEALS}

The development and use of pre-prepared, chilled, ready-meals has been a major factor in the changing eating habits and life-styles of millions of consumers, particularly in the UK. The development involved radical, but largely unrecognised technological change and has also been a major factor in the evolving domestic and 
international operations, costs, profits and relationships of many business companies including supermarkets, packaging developers and suppliers, food technologists, refrigeration engineers, growers, food producers and logistics companies. Most of the companies involved in the development knew each other well and many had done business together over many years. The widespread adoption of chilled ready-meals involved many and varying combinations of companies. For example, supermarkets and food producers worked together on issues of product and range design and production technology. These companies together with market researchers and advertising agencies were also concerned with promoting to consumers and to each other the advantages of chilled ready-meals and the quality of particular brands. Some of these companies also worked with distributors, growers, packaging-design and production companies to address questions of food safety and security, whilst refrigeration engineers and supermarkets were concerned with ways of enhancing display, shelf-life, energy conservation and waste reduction in store.

The development was conditioned by the particular context in which it took place, during a time when the margins of grocery producers, distributors and retailers were under pressure as competition between supermarkets increased. But it would be impossible to identify a single starting time or reason for the development which had multiple origins in the previous patterns of business and the current pre-occupations of many companies. No single actor controlled the process, but many tried to influence its direction with greater or lesser success. The development had identifiable outcomes for many actors. These outcomes were not final, but instead formed inputs into subsequent patterns of business between many of the directly involved companies and others. Some of this subsequent business involved deliveries of raw materials, packaging and finished products as new varieties of ready-meals 
were introduced and as additional companies became involved. Some of these further developments were international and some led to profound changes in the structure and operations of companies and consumers. For example, purpose-built 'food-only' supermarkets emerged, often located at railway stations for the service of returning commuters. The frozen-food industry was decimated by the development, specialist deli-retailers declined and many restaurants and pubs lost business. The remaining catering industry changed as new companies offered a wide range of prepared and semi-prepared meals, which they produced themselves or sourced from companies that also supplied supermarkets. This development meant that less-able restaurant cooks could emulate the food served in better restaurants and better restaurants could reduce their costs by preparing fewer items on-premise.

\section{Analysis of the Case Study}

A conventional marketing management analysis would probably characterize this case study as an example of one or more manufacturers competing with each other to achieve sales and profits in a number of separate but related markets for particular intermediary or end-products. Within this analysis, retailers would form part of the distribution element of the marketing mixes of those manufacturers (Borden, 1964; McCarthy, 1960; Grönroos, 1997; Gripsrud, 2004). Other companies in the case would be viewed within the context of the product development and purchasing operations of these manufacturers.

But more recently, the Service Dominant Logic (S-D Logic) literature closely associated with Vargo and Lusch (2004, 2006, 2008, 2011; Grönroos, 2008) has 
suggested that greater insight into the nature of the business process can be achieved by re-orientating analysis away from an emphasis on products and towards one of service delivery and value creation (e.g. Vargo and Lusch 2004, 2006). This view would mean that the tangible products involved in the case study; ready-meals, packaging materials, delivery trucks, meat and vegetables would be regarded as delivery mechanisms for service (Lusch and Vargo 2006, pp. 283-4). Service would then be considered to form a basis for creating unique value for a particular customer. However thus far, the literature on SDL has not elaborated on the characteristics of service or the nature of the value-creation process or of value itself, although Vargo and Lusch have raise this as a question (2008, p. 451). More recently, Grönroos, (2011a; 2011b) has developed ideas on the complexity of the concept of value, within a uni-directional (from producer to consumer) business process in which he suggests that the customer as the user of resources is the value creator.

However, Vargo and Lusch (2011) have called for the development of a 'system perspective' of markets in which both of the counterparts involved in an exchange relationship are at the same time producers and consumers of service. This approach would view the case study as depicting a collection of markets in which dyadic transactions took place for the exchange of service and provision of value. Vargo and Lusch also suggest within this system perspective that actors could, "invite other actors to assist in the production of service offerings” (2011, p.185).

An analysis of the case study based on the empirical research of the IMP Group (e.g. Håkansson, 1982; Håkansson and Snehota, 1995; Ford, 2011) would also take a systemic view. This view would interpret the case study as a series of interactive episodes within an evolving network of interdependencies between the actors 
involved. IMP literature would emphasise the heterogeneity of these interdependencies, each developed through multiple problem-coping interactions within continuing relationships (Håkansson et al., 2009; Mouzas and Ford, 2009).

The emphasis on heterogeneity, the importance of specific counterparts, the complexity and long-term nature of business interaction militate against generalisations about particular categorise of actors such as 'customers', 'suppliers', 'manufacturers' or 'retailers', about their interactions. Hence, IMP research would be concerned to examine the idiosyncratic 'Network Pictures' (Ford et al., 2003, Leek and Mason, 2009, 2010) held by the actors within their 'small world' (Migram, 1967; Håkansson et al., 2009) which form the basis of their approaches to interaction.

The IMP analysis would suggest that the small world of the business actors in our case does not exhibit the characteristics of a market nor is it simply an agglomeration of many markets: Its structure is not one of independent companies that have ease of entry or exit from the market or from their dealings with specific counterparts as marketers or customers. Instead, the analysis would emphasise that many of the actors in this small world would have become interdependent with each other through their business together. The pattern of interdependencies across these small worlds and the perspectives that arise from them form the context for continuing interaction and the developments outlined in the case. This analysis would also emphasise the narrow, but permeable boundaries of each actor's small world. This narrowness and permeability emphasises the limited horizons of all actors and the importance of intermediaries in interaction. It also emphasises that interactions, relationships and interdependencies are limited by the number of immediately available counterparts. 
For example, in our case study there are only four major supermarket groups in the UK and only a few large-scale food producers or refrigerated distributors.

\section{SUBSTANTIVE INTERACTION AS THE BASIS FOR SERVICE AND} VALUE WITHIN A SMALL WORLD

IMP research emphasises that the dyadic and multilateral interactions in business are not restricted to communication, negotiation or to specific transactions. Business interactions are substantial (Ford and Håkansson, 2006b; Ford and Mouzas 2010). In other words, they each involve a number of different aspects of the activities and resources of the actors. Each of these may be changed and transformed through interaction as the actors adapt, invest, learn, teach, coerce and concede to particular counterparts as their interactions evolve. We can use the structure in Table 1 to describe the substance of business interaction and relate this to the case study and to the concepts of service and value: 
TABLE 1: CHARACTERISTICS OF SUBSTANTIVE BUSINESS INTERACTION

\begin{tabular}{|c|c|c|}
\hline & $\begin{array}{l}\text { INTERACTION AT A } \\
\text { POINT IN TIME } \\
\text { CHARACTERISED BY }\end{array}$ & $\begin{array}{l}\text { EVOLUTION OF } \\
\text { INTERACTION } \\
\text { CHARACTERISED BY }\end{array}$ \\
\hline ACTIVITY & Interdependency & Specialisation \\
\hline RESOURCE & Heterogeneity & Path \\
\hline ACTOR & Jointness & Co-evolution \\
\hline
\end{tabular}

Thus the development of chilled ready-meals built on some of the pre-existing interdependencies between the activities of the actors in particular relationships directly within the actors' small world and indirectly across the wider network. The process involved heterogeneous resources that had been specifically adapted within 
particular relationships and it involved actors that worked jointly together with consequent limitations on their autonomy.

The development of ready-meals would change aspects of the activities, resources and the actors involved in this small world. Some activities such as the production systems of food producers will have become more or less specialised towards the requirements of particular counterparts, others less so. Resources, such as the stockholding facilities of producers, retailers and logistics companies will have followed a particular path of investment or development and the actors themselves will have co-evolved ${ }^{1}$. Co-evolution does not refer to an inevitable increase in the 'closeness' of the relationships between interacting actors. Rather, it suggests that the operations, characteristics and attitudes of business actors evolve as an outcome of their interactions over time and are affected by the multiple interaction episodes in the development in our case. For example, many aspects of the organisation of growers, food producers and logistics companies evolved as their operations became more interdependent through this development.

The Wider World: Our case study described some of the interactions that took place over a period of time within the evolving small worlds of a number of diverse actors. All the actors we introduced and the relationships and interdependencies between them are part of a wider network (Håkansson and Snehota, 1995). However, each of these actors will have a very restricted picture of this 'wider world' and each has no direct interaction with the actors within it. For this reason, each actor will be

\footnotetext{
${ }^{1}$ The evolution of resources through interaction in the IMP view is neatly encapsulated by Vargo and Lush (2011/2004) "resources are not: they become"
} 
dependent on service provision by some of its immediate counterparts who have relationships with or provide access to others at a distance. For example, the producers of ready-meals are likely to depend on their relationships with packaging companies to gain access to the activities and resources of packaging materials companies. Similarly, logistics companies will depend on their relationships with trailer suppliers to access the skills of vehicle refrigeration contractors. Access to the wider world is the classic role of systems integrators and distributors. The wider world of the business network is made up of the myriad small worlds of other actors, each of which is comprised of interlocking interdependencies within which service may be provided and value created.

\section{BENEFITS, COSTS, SERVICE AND VALUE}

We will now attempt to develop the concepts of service and value within the context of the interactive business landscape which we have outlined and relate these concepts to our illustrative case study. We start from the position that the concepts of service and value contribute little to an analysis of the substantive interaction within the business process, unless they can be developed, refined and related to the empirical situation of an interactive business landscape: it is insufficient to simply assert that value is proposed and service is provided (Vargo and Lusch, 2011).

This refining would have to accommodate at least the following:

The multiplicity of motivations that may lead actors to seek or contribute to service provision and the factors that may underlie actors' different perceptions of the value of the service in which they were involved. 
The nature of service and value within a short term or transactional context and also as part of longer term relationship and network evolution;

The costs of service and disservice to those who seek or offer service and the process through which trade-offs, reciprocity, sequencing and mutuality emerge in service and value provision.

The connections between the actions, reactions and re-reactions of single and multiple actors which are intended to achieve change in relationships and in the provision and receipt of service and value.

The case study of the development of ready-meals illustrates many aspects of this complexity. For example:

Some of the actors in our case study may have preferred to avoid any involvement in the development of ready-meals, but are involved through their existing relationships within their evolving small world. Others may have been pioneers or enthusiastic participants at various times either directly with counterparts or by working with, through, against or in-spite of others. Some of the actors may have identified a shortterm opportunity for financial advantage in a particular 'good deal' in one aspect of the process, perhaps involving the purchase or sale of equipment or suppliers, maybe to the immediate or perhaps long-term disadvantage of a direct counterpart or someone elsewhere in their small world. Some actors may have sought to benefit from the development through adaptation or investment by themselves or their counterparts in one or more of their relationships. Others may have accepted major costs of disruption or development in order to achieve long-term benefits for themselves, for particular counterparts or for their small world as a whole as the 
development proceeded. Some may have had little or no identifiable involvement in the development but may have benefitted or lost out considerably. Some of these costs and benefits could be easily quantified, for example in terms of sales, profits or purchase prices. Others would be more difficult to assess, such as the benefits of improved understanding between customers, suppliers or development partners.

Service Seeking and Actor Problems: Research within the IMP literature leads to a view of interaction in business relationships as a unique, evolving, multifaceted process of 'problem-coping' by and for all of the involved actors (Webster, 1965, p. 371). Thus for example, a supplier may view its relationship with a particular customer solely as a way of coping with its own immediate cash-flow problem or as an arena in which to exploit a particular combination of its own or a counterpart's activities and resources. It may see another customer-relationship as a means of addressing a continuing problem of long-term technological development for either or both of the companies or as a way of coping with unforeseen occurrences as they arise. The term 'coping' is used to emphasise the interactive and evolving nature of business problems. Thus the efforts of one counterpart in a relationship to address a problem are unlikely to be successful without the efforts of a specific counterpart(s), which may be more or less forthcoming (Grönroos, 2011). Also, an apparently successful problem 'solution' at a particular point in time may appear quite different at a later time. Similarly, the problems of business actors are unlikely to be completely 'solved' and different interactions may produce different coping mechanisms that will involve more or less benefit, more or fewer side-effects and more or less costs. 
Each actor faces choices over which of its own and its counterparts' problems it will choose to confront and in which relationship it will attempt to do so. The complex, evolving and interactive nature of problem-coping also mean that each actor will also have to conform to the status quo in many aspects of its relationships for which problems cannot immediately be addressed (Håkansson and Ford 2002; Ford and Mouzas, 2006, 2010). But IMP empirical research has also suggested that actors are likely to look within their existing relationships when new problems arise (Håkansson and Snehota, 1995).

Business interaction is the process through which each business actor will seek or offer service to or from particular counterparts on the basis of specific problems it has recognised and chosen to address and the particular relationships within which it is engaged. Service-seeking and offering is based on the existing resource heterogeneity, activity interdependence and actor jointness in relationships. Serviceseeking and offering drives the process of activity specialisation, the path of resources and the co-evolution of actors. But of course this process is complicated because an actor recognising a particular problem or a counterpart may or may not have a view of how a problem could or should be addressed!

The role of service-seeking and service provision as a mechanism for problem-coping is not restricted to specific transactions. Empirically, the most significant problems that actors face concern the relationship structure in which they are embedded ${ }^{2}$, rather

${ }^{2}$ IMP research has suggested that the business actor should be viewed as a node within a network of relationships, so that what happens outside the actor and through its relationships is likely to be more important in the evolution of that actor than what happens inside (Håkansson et al., 2010). 
than any specific transaction within them. Thus, actors are likely to devote considerable attention to problems relating to the development of activity specialisation, resource path and actor co-evolution. This problem-coping is likely to be long term and the service that an actor may seek from or offer to a counterpart may involve significant resource, activity or actor investment, adaptation or even transformation. IMP research uses the term 'business networking' to refer to the attempts of actors to change the structure and process of the relationships in which they are involved. It is through business networking that actors seek to cope with their problems and those of others (Ford et al., 2011).

\section{Reciprocity}

Business interaction involves all actors in trade-offs between their own short and long-term problem coping and that of others. All problem-coping involves costs for all of those involved in it: in the short-term, dyadic problem coping may centre on a single transaction involving the costs associated with transferring cash for one counterpart and the benefits of service for the other. Alternatively, short-term problem coping may involve working together to solve a particular technical problem for mutual benefit. In contrast, short-term problem coping may appear to involve only one actor in benefits and one in only costs. However, these short-term costs and benefits received will affect both actors long-term view of their relationship, their attitudes to investments in it and to expectations or reciprocal 'pay-offs' from it. In the longer-term, problem coping will be based on investments and adaptations by the counterparts in one or more aspects of the substance of their interaction (Hughes, 1987; Mouzas and Araujo, 2000). Business actors commonly face issues over the trade-offs between potential and actual short-term and long-term costs and benefits of 
the counterparts in a relationships, expressed in terms of the extent and timing of respective activity specialisation, resource path or actor co-evolution.

\section{VALUE}

Previous research offers a plethora of relevant theoretical insights to make sense of the term value (Anderson and Narus, 1999; Mnookin, Peppert and Trumello, 2000; Lepak, Smith and Taylor, 2007; Henneberg et al., 2009). In general terms, 'value' is considered as the perceived worth, often expressed in monetary terms of a set of psychological, functional or economic benefits received in exchange for price paid or sacrifices made, based on the recipients specific problems as well as competitive offerings and prices (Anderson and Narus, 1999).

According to Vargo and Lusch, (2008, page 8), “...the value (of service) is always determined by the beneficiary of service”. The value to a participant from service is, therefore, not a characteristic of what is involved in it, whether product, services, payment or generalised 'performance'. But an interactive and systemic conceptualisation of the business process requires a refinement of this view of value, as follows:

Value of Problem Coping: If interaction is a problem-coping process then the value to each actor of a service is that actor's interpretation of the worth of the service's contribution towards coping with one or more specific problems of the actor, identified by that actor. Hence the value as the 'perceived worth' of the same service received by different respondents will be different and in all cases that value is time and problem-specific. Empirically, the idiosyncratic 
nature of service value to a counterpart poses great difficulty for the provider in business interaction.

Value and Reciprocity: The value of service is not determined solely by the receiving actor. Each interacting actor is likely to make their own assessment of the problem-specific value to themselves and to their counterparts of a service that they seek or provide. These multiple assessments will form the basis for their approach to interaction in any single episode and to their expectations and intentions for future episodes and a relationship as a whole. Of course there is no necessary reason for these assessments of value to be the same and differences between them are an important basis for argument and relationship conflict.

Incidental Value: The business landscape is characterised by recurrent interactions between multiple actors in continuing relationships. Service provision and value creation in any of these may lead to incidental value to others, either positive or negative and in line or against the wishes of those involved.

Business actors often agree formally or informally about the costs and benefits that would accrue to them and when they would accrue (Sander, Peppet and Tulumello, 2000). In other words, they agree the service that each would receive as an outcome of that interaction. For example in our case study, a development engineer may have agreed with a food manufacturer and a retailer that they would work on the development of a package for semi-liquid food that would give five days of shelf-life and that was microwavable. In return, the manufacturer and the retailer may have agreed that they would transfer food technologists to the developer to assist in the 
work, provide sample foods and prototyping facilities and if the development was successful, they would pay a lump-sum fee for the development and a licence fee for subsequent usage. It is possible that some of the actual service provided and received in this development and its timing would approximate to agreements made by the actors beforehand and to their expectations of themselves and their counterparts. But it is likely that actors would perceive that much of the service actually provided fell short of their expectations or exceeded them. Unforeseen contingencies (Maskin and Tirole, 1999, Tirole 2009) might explain this; the delivery of services or products may have been late, cooperation may not have been forthcoming, adaptations may not have been fully carried through, payment may have been less than expected. In contrast, technical assistance could have produced greater than anticipated cost savings or a cooperative development could have enhanced an actor's relationship with a third party.

Business actors may attempt to analyse service provision for themselves or their counterparts in terms of either its general or specific value. For example, the recipient of service in the form of payment may note its contribution to the general financial well-being of the company. But the same recipient may have a very different perception of the same payment if he considers it to be important in coping with a short-term cash flow problem. However, the counterpart that made that payment may not appreciate its impact on the company's cash flow. Thus perceptions of service will vary between actors and these different perceptions will be important inputs into an evolving interaction process and the network pictures of the participants). The existence of different perceptions among actors explains why profitable business opportunities may exist whenever prices fail to reflect the value of a resource's specific use (Denrell, Fang and Winter, (2003). 
Building on previous conceptualizations of value and the IMP research we suggest that the value of service may be identified at the following levels:

Episodic Service Value: Service provision within a particular interaction episode (whether or not it involves product, service or payment) may have immediate value for each of the actors involved in that episode, depending on each actor's perceptions of the episode's contribution towards coping with its specific problems. Episodic service value is not an automatic outcome of business interaction. Instead, value creation within an episode is the outcome of the particular problems that the networking actor chooses to confront rather than to conform to current ways of operating.

Relational Service Value: Continuing or long-term interaction also contributes service for either one or both counterparts in a dyadic relationship by developing the potential value of the relationship for future episodes (Henneberg et al., 2009). Relational value at any one time will depend on the interdependence of the counterpart's activities, the heterogeneity of their resources and the jointness of the actors (Ford et al., 1986; Ford and Håkansson, 2006a; Håkansson et al., 2009).

Service Value in the Small World: All actors face choices in their small world about when to consolidate their interactions within their existing relationships and when to attempt to change their pattern of relationships or to develop new relationships. The costs and time involved in new relationship development often limit networking opportunities to existing relationships. However, problem coping in the business landscape can never be wholly dyadic. The service offered by a single actor to another always depends on service 
provision from within that actor's other relationships. An obvious example of this is seen in the dependence of product suppliers on components supplied by others. Similarly, all value-seeking actors rely for the creation of value on their interactions within other relationships. IMP research (Vercauteren, 2007; Awealeh et al., 2006; Ford et al., 2011) has demonstrated empirically the creation of value for an actor by changing multiple actors within an actor's small world by using one or more relationships to achieve change in others.

Service Value in the Wider World: The connections between a single relationship and others within the wider pattern of activities, constellation of resources and web of actors across the network lead to a fourth level of service value. Service in any single episode or process may provide incidental value or produce costs for actors in other interaction processes and to other actors in connected processes elsewhere in a business network. An actor may also choose to produce these effects by its networking. However, because of an actor's lack of knowledge or established relationships in the wider world, this networking will either be based on relationship development or service provision by others.

The connections between business interaction, service and value are summarised in Table 2. 
TABLE 2: THE CONNECTIONS BETWEEN INTERACTION, SERVICE AND VALUE

\begin{tabular}{|c|c|c|}
\hline $\begin{array}{c}\text { BUSINESS } \\
\text { INTERACTION }\end{array}$ & SERVICE & VALUE \\
\hline $\begin{array}{l}\text { The problem-coping } \\
\text { process of actions, } \\
\text { reactions and re-reactions } \\
\text { between actors }\end{array}$ & $\begin{array}{l}\text { The successive outcomes } \\
\text { of business interaction as } \\
\text { perceived by the } \\
\text { participants }\end{array}$ & $\begin{array}{l}\text { Each actor's perception of } \\
\text { the contribution of service } \\
\text { to coping with the specific } \\
\text { or general problems of } \\
\text { particular actors at four } \\
\text { levels: } \\
\text { 1. Episodic } \\
\text { 2. Relational } \\
\text { 3. Within the Small } \\
\text { World } \\
\text { 4. Within the Wider } \\
\text { World. }\end{array}$ \\
\hline
\end{tabular}




\section{AN EMPIRICAL STUDY OF SERVICE AND VALUE IN THE BUSINESS LANDSCAPE}

\section{Methods and Setting}

We will now attempt to use the ideas on service and value developed in this paper to examine a second case of change and evolution in a particular small world in Germany. The actors in this small world include fast-moving consumer goods producers such as Procter and Gamble, Unilever, and Henkel and grocery retailers, such as Wal-Mart, Metro, Rewe, Tengelmann and Aldi (Villas-Boas and Zhao 2005; Hingley, 2005).

One of the most intriguing empirical findings during our investigation of this small world was that the interdependent actors did not express their concerns in terms of individual products or services. Instead, their concerns involved multiple and sequential problem-coping by and for varying combinations of business actors leading to a wide range of service provision and value creation. This finding encouraged closer examination of service between three manufacturers and two major retailers as well as a group of other retailers. By using case study research methods (Yin, 1994; Tsoukas, 1989; Ragin, 1992; Easton, 2010; Halinen and Törnoos, 2005; Gibbert, Ruigrock and Wicki, 2008), the research looks at interactive processes of service provision. The case study method is particularly suited to the purposes of the present research, because we were concerned with "a contemporary phenomenon within its real life context, where the boundaries between phenomenon and context are not clearly evident and in which multiple sources of evidence are used" (Yin, 1994 p 13). 
The interviewees included business managers such as Business Unit Directors, Category Managers, Information Technology Managers, Sales Directors, Purchasing and Supply Directors, Key Account Managers.

Data analysis of the case produced three major challenges: the problem of network complexity; time and comparison. Interactions between companies are exceedingly time-consuming; they are individualized and often recurrent. For this reason, we focused on three multi-national producers of laundry and cleaning products and two major German retailers and analysed the dynamics of the interactions as well as the inter-connections in clusters to generate reliable comparisons. When the first draft of the case was finalized, feedback interviews with the senior managers were conducted to check our interpretations. This feedback proved extremely relevant in fine-tuning our interpretations and testing the internal validity of our findings. However, our interpretations are not seeking empirical generalisations, but to illustrate the use of particular concepts which are themselves analytically generalizable (Tsoukas, 1989)

Figure 1 illustrates some of the actors in this small world: P\&G, Henkel and Unilever are three multi-national producers of laundry and cleaning products; Tengelmann, and Aldi are two major German retailers. 
Figure 1 : The Small World

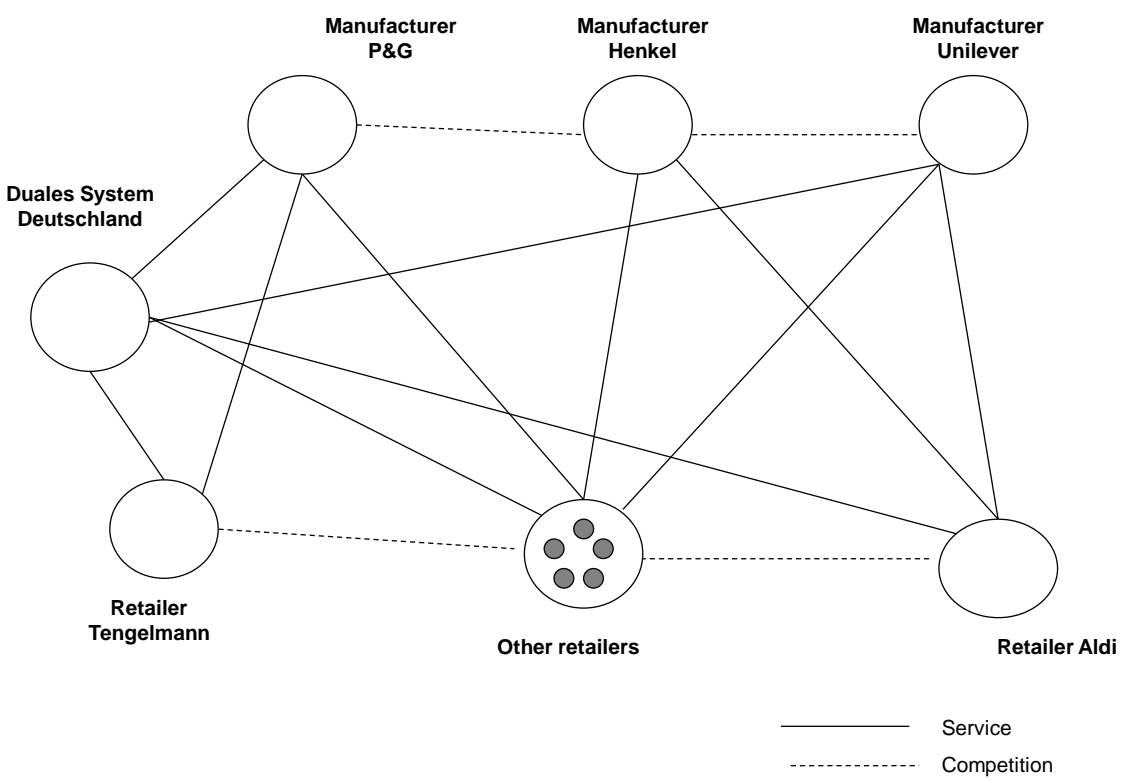

Manufacturer P\&G's flagship laundry detergent Primus had experienced sales and market share declines while Henkel's major brand Aristo was consistently market leader with $32 \%$ market share. P\&G blamed its decline on the absence of superior service to consumers and retailers and its consequent inability to generate strong consumer interest and trade support. For this reason, P\&G examined the option of trying to re-develop Primus's customer-base by reorienting its offering to provide service through coping with the environmental concerns of consumers and the wish of retailers to be or to appear to be environmentally friendly. This option had originally emerged during interactions with retailer Tengelmann. Tengelmann's environmental interests dated back to the late 1980's. At that period Tengelmann had exercised enormous pressure in its relationships with detergent manufacturers for them to produce phosphate-free detergents.

To evaluate the feasibility of this approach to consumers, P\&G invested heavily in consumer research conducted by GfK Market Research and ACNielsen, two leading 
market research organizations in Germany. A series of in-depth behavioural studies confirmed that environmentally conscious consumers valued environmentally friendly offerings and were prepared to pay higher prices for them, but they increasingly valued only credible and tangible solutions for environmental problems and rejected empty promises. These research findings, prompted $P \& G$ to capitalize on the experience of its parent company in the USA, and incorporate the environmental variable into its manufacturing processes and in all aspects of packaging and product development.

P\&G’s key account managers and Tengelmann’s purchasing managers negotiated over the listing of environmentally-friendly brands. The negotiations were successful and focused on the trade allowances for the retailer in return for extending the product range that it listed. Two months after launch of environment-friendly brands within Tengelmann, the first Nielsen data on consumer off-takes of the brand indicated a growing demand. Consumer off-take data were also available to all market participants, including Henkel and Unilever. Building on this positive momentum, P\&G then extended the launch of a series of new environment-friendly brands to all other retailers, using the available consumer data as supporting evidence in its negotiations. P\&G estimated that if all households would use the environmentfriendly detergent, labelled Primus Ultra, then 160,000 tonnes less detergent and less packaging would be released into the environment. Furthermore, manufacturer P\&G increased its marketing support for Primus liquid and launched an un-perfumed line extension. Finally, P\&G launched refill packs for all its products in response to increasing environmental concerns from consumers and government legislation. 
Environmental legislation in Germany, reflecting a change in consumers' attitudes and demand, has been the catalyst that has speeded up the emergence of an environmental orientation by retailers and manufacturers. Under the Waste Packaging Regulations, both manufacturers and retailers are equally responsible for protecting the environment. The responsibility for disposing of packaging materials has meant an increase in handling costs for retailers. The trade, as an intermediary between consumers and manufacturers, has tried to pass on these extra costs to manufacturers. Manufacturers have responded to the new situation in collaboration with retailers through the establishment of the Duales System Deutschland - that grants licences to put a so-called Grüner Punkt (green dot) on packaging so that consumers know they can dispose of the packaging in DSD bins.

Nonetheless, P\&G's managers had not relied solely on the environmental argument in their effort to roll-out their services. P\&G's key account managers introduced the new detergents to retailers by using the following arguments: Firstly, the new products would increase turnover and profit per square metre of store space, both perennial issues for retailers. Secondly, according to the analysis of off-take data from Tengelmann's scanner terminals, consumers that bought Primus Ultra also purchased a basket of other products that was worth 116 Euro; while consumers of conventional detergents purchased a basket that was worth 59 Euro. For the retailers this meant that P\&G's environment-friendly innovations would also contribute to more volume and profit, and they welcomed the series of line extensions and new brands.

The intensified re-launches of manufacturer $P \& G$ were first interpreted by manufacturer Henkel as a desperate move to regain consumer attention. Nevertheless, P\&G's triumphant roll-out to other retailers caused considerable anxiety within 
manufacturer Henkel. Henkel's most relevant brand in the laundry and cleaning category, Aristo was not only a leading detergent in Germany it was also the brand with the greatest heritage. It was a brand that was a legend and symbol for the company in its relationship with consumers. No one from Henkel's senior managers wanted a race for launches and re-launches because they were concerned that this would cause a cannibalization among Aristo’s sub-brands. Henkel's senior managers, however, felt that under these conditions they had no other choice but to rethink their existing approach.

Henkel's managers felt that they couldn't accept the risk of losing market leadership. They assessed the risk of cannibalization among Beta's brands as being more acceptable than the risk of losing their market share due to inertia. In their assessment of options, Henkel's senior management emphasized that competitive response should take into account three fundamental needs: Firstly, the need to keep the distinctiveness and uniqueness of Aristo's brand positioning. Henkel's top management argued that they were still market leader, because the Aristo was a detergent that coped best with the problems of fabric protection and colour fastness for consumers. Secondly, the need to respond if it became evident that competitor P\&G was gaining a share of the market on a sustainable basis. Thirdly, there was a need for real service innovation. After seven months, manufacturer Henkel responded with an aggressive 'me-too' approach, but staying very close to their brand positioning philosophy.

The result of all these interactions was that an increasing number of product variations pushed their way on to retailers' shelves. The new environment-friendly detergents caused anxiety in Aldi's management. Retailer Aldi knew that GfK consumer 
research indicated that environmentally conscious consumers bought detergents more frequently from retailer Tengelmann (23 \%) than from Aldi (9\%). But also, a significant proportion of environmentally conscious consumers bought their detergents from specialty shops (17\%). It became apparent to Aldi that if it wanted to succeed in a fast-moving consumer goods environment such as the laundry and cleaning category, then it needed to work closely with a manufacturer that would provide the retailer with competitive private labels according to the latest technology.

In this respect, $P \& G$ would have been an ideal partner for Aldi. However, $P \& G$ did not produce private labels as a matter of principle and, therefore, Aldi had never listed P\&G's products in its retail outlets. It was, therefore, impossible for the two counterparts to work together. In comparison, Henkel used private labels in the past as a Trojan horse to build business with key retail counterparts but Aldi excluded fullprice manufacturer brands in order to promote strong private labels. For this reason, Henkel felt that Aldi's policy was to turn manufacturers into mere production subcontractors of their retail operation. Similarly, producing private labels for Aldi was seen by Unilever as a step towards building up a substantial volume base. The difference, however, was that Unilever, despite its leading position in many consumer segments, had only a minor share of the market in the laundry and cleaning category.

Manufacturers were by now investing a great deal in advertising for both old and new environmentally-friendly brands and retailers were coerced by the manufacturers to list all of them. The intensified launches and re-launches led to overcrowded shelves for detergents and produced caused considerable conflicts between the retailers' purchasing departments and the manufacturers' sales functions. This situation made the need for transparency and rationalization within existing categories clearly 
evident. Consequently, manufacturer P\&G started to consider category management with retailers and Tengelmann also conducted a series of pilot projects which were then extended more widely. The objective of these extensions was to reduce the problem of overcrowded shelves and frequent friction between the retailers' purchasing and sales. Furthermore, Tengelmann considered the creation of a new department that integrated sales and purchasing and which was based on the principle of category management. Within two years, P\&G's approach to retailers included new elements such as: exclusivity of services, co-operation with retailers' sales managers, development of shopper insight (an intelligence service that examined consumer behaviour at the point of sale) and customer profitability analysis.

\section{Case Analysis}

The complexities of the case study and all interaction processes mean that we can only give an outline analysis here, centring on the different levels of service and value, as follows:

The Context: The Small World and the Wider World: The case describes complex interactions within a number of interconnected relationships between interdependent actors in a small world. The initial problem with which P\&G tried to cope related to its continuing interactions over many years with a number of counterparts, including retailers, consumers and other suppliers. Its attempts to address this initial problem not only required interaction with specific counterparts, but also led to a succession of interaction episodes between other actors in some of which $P \& G$ was directly and in others indirectly involved. All of the interactions within this small world were affected by the interventions of the German government which also affected interactions, service and value for actors in separate but connected small worlds. 
Episodic Service Value in P\&G's Initial Interactions: P\&G's initially networking was aimed at confronting its problem of declining sales in a particular relationship with Tengelmann by seeking the retailer's cooperation in the development and introduction of Primus Ultra. In this episode, service provision for P\&G took the rather ephemeral form of support and encouragement. But this was sufficiently valuable to $P \& G$ for it to approach its parent organisation for assistance with development. There was no immediate value to Tengelmann from its response in this episode, but there was the prospect of long-term value in its relationships with P\&G and consumers if environmentally sensitive products could subsequently be introduced. The value of $P \& G$ Headquarters assistance to $P \& G$ Germany from this episode could readily be expressed in the short-term time and cost savings that ensued for P\&G and the prospect of longer-term revenue growth for corporate P\&G.

Associated Relational Service Value: These two episodes immediately illustrate the connections between episodic and relational value. Firstly, P\&G was able to successfully approach both counterparts on the basis of their substantial interaction in the past and in particular on the jointness to which it had led. Secondly, the interaction episode that centred on the successful product launch would have created further relational service value for P\&G and Tenglemann as potential for future interaction. Thirdly, P\&G's networking to cope with the problem of environmental responsibility did not take place in isolation and both companies continued to confront other problems through their interactions. However, each had to conform to the status quo in areas where change would be unacceptable to their counterpart.

Interactions in the Small World: P\&G's initial interactions with Tengelmann produced value for both companies in their relationships with consumers who were of 
course major actors in this small world. The initial episode with Tengelmann also led P\&G to introduce the environmental product in its relationships with a number of other retailers in its small world, leading to mutual value creation. However, the uniqueness of business relationships meant that similar service provision and value creation involving the same product did not take place in those situations where previous relational value had not been created, as in the case of $P \& G$ 's relationship with Aldi.

Related Interactions in the Small World: The business landscape is characterised by interconnected business relationships as we observed in the ready-meals case. In this case, the initial networking of P\&G led to further networking by manufacturers and retailers in this small world based on their respective interpretation of the problems that had arisen in their own relationships with each other and with consumers. Some of this networking by Henkel and others was intended to offer similar service to retailers. However, this service provision and the value that may have arisen led to longer term costs for both suppliers and retailers and associated deterioration in their relationship value as ranges and varieties multiplied.

Consequential Interactions: The case emphasises that the analysis of service provision and value creation cannot be confined to a single transaction or even a series of transactions. In contrast, the case demonstrates the complex sequence of business networking and the associated service provision both within particular relationships and between relationships in the small world. Thus the value creation arising from product range enhancement originating in P\&G's original confrontation of their problem with Tenglemann led to further interactions between manufacturers and retailers. These interactions led to problems for manufacturers and retailers led to 
major relational service value creation as activity interdependence, resource heterogeneity and actor jointness increased through P\&G's development of category management with Tenglemann.

Actors in the Wider World: We have emphasised that no small world is isolated from the wider world. In this case, a major intervention from outside the small world came in the form of new regulations on packaging and recycling from the German government. We have also noted that actors within a small world know little about the wider world and are often dependent on intermediaries to interact there on their behalf. In this case, actors within the small world attempted to interact with the Government collectively or via their trade association to minimise the costs and maximise any possible value from this episode.

\section{Network Pictures, Network Position, Service and Value}

The case study reinforces a view of the self-serving characteristics of problem coping in the business landscape. Rather than being simply 'market oriented' 'value proposers' (Vargo and Lusch, 2004, 2006), the case illustrates the diversity of actor's positions in their small world, the different pictures of that world, the limitations and opportunities for problem coping that arise from them. The network pictures of actors have been shown to take a wide variety of forms (Henneberg et al., 2006; Mouzas et al. 2008; Leek and Mason, 2009; Oberg et al., 2007; Henneberg et al. 2010). Pictures may be expressed as a static view of a current situation, a view of past evolution, current direction, ideal state or appropriate behaviour. Network pictures thus not only formed the basis for the holder's approach to interact, but also for the assessment of the legitimacy of the approaches of others. In this case, $P \& G$ viewed private labels as detrimental to the maintenance of strong brands and so ultimately against consumer 
and manufacturer interests. Hence, it did not produce them as matter of principle. This prevented the development of any significant relationship between $P \& G$ and Aldi which only stocked private labels. Similarly, Henkel felt that Aldi's policy was to turn manufacturers into mere production subcontractors and hence was not in the best interests of 'the industry'. In contrast, Aldi believed that Henkel had used private labels in the past only as a 'Trojan horse' to build business with key retail counterparts but Aldi excluded full-price manufacturer brands in order to promote strong private labels. For this reason, producing private labels for Aldi was seen by Unilever as a step towards building up a substantial volume base. The difference, however, was that Unilever, despite its leading position in many consumer segments, had only a minor share of the market in the laundry and cleaning category.

\section{CONCLUSIONS}

This paper has tried to address the particularities of service and value in the interactive business landscape by building on conceptual developments within previous IMP research. An interactive view of service shifts the emphasis in business analysis from the characteristics of what is provided by one actor (usually a supplier) for another (usually a customer) to what is received by all counterparts within and through their interaction. What are the theoretical implications of this shift in emphasis?

Firstly, the conceptualisation of service in an interactive business landscape allows us to capture the inherent connectivity among interdependent business actors. Service is 
the successive and reciprocal outcome of recurrent interaction as perceived by the involved business actors.

Secondly, the idea of service in an interactive business landscape transforms our view of the process of value creation and appropriation in networks. The value of a service is not confined to one company as the apparent receiver (Vargo and Lusch, 2004, 2006); instead, service can be of different value to multiple actors, including the apparent provider. Both are involved in service, both incur costs and both receive value (Vargo and Lusch, 2011; Ford, 2011). Nor is the value of service confined to the episode in which service is provided. A particular interaction episode that provides immediate value (Grönroos, 2011) is also likely to change the nature of the relationship in which it occurs, leading to relationship value. However, there is an important trade-off involved here: A business actor may seek to gain immediate episodic value by taking short-term advantage of a counterpart, only to incur negative relationship value as the counterpart responds.

Thirdly, taking an interactive approach to service allows us to investigate the dynamics of problem coping and creation. The evolution of problem-coping is observable through a continuing and cycle of recurring episodes and evaluations over time (Mouzas and Ford, 2009). For management, the idea of service in an interactive business landscape emphasizes the importance of analysing the evolving problems and uncertainties of specific actors and the perceptions of those involved in the interaction. Moreover, service highlights interaction in continuing relationships as successive, reciprocal, outcomes of action, reaction and re-reaction as counterparts choose which of their issues or problems to confront and for which to conform at particular times. Success in these choices requires perceptive analysis of relationship 
evolution, of the problems of the company and its counterparts and a well-developed, explicit but flexible agenda. Service in an interactive business landscape also involves a managerial re-orientation away from things, products and services and towards the evolving problems of the company and its specific counterparts. A view of service in an interactive business landscape emphasises the variety of forms that service can take in business and the range of opportunities that it offers to management. Service provision can range from obvious manifestations, such as the payment of an invoice, the delivery of a product or the development of a new technology to the subtle or complex, including the provision of advice or reassurance, organisational transformation or intellectual assets, know-how and expertise (Mouzas and Ford, 2012). But in all cases, the nature of service delivery is defined by the recipient and its value is determined by the problems of the recipient to which it is addressed, immediately, or in the future or in other contexts. An understanding of the concept of service and value in an interactive business landscape enables managers to relate their own resources and activities to those of others as the basis of coping with their respective problems.

We have used two case studies to highlight problem coping and service provision through interaction. The cases show that the way that companies in a relationship address particular problems can lead to the emergence of problems for other companies in the network. The cases also shows that service provision can lead to new problems for the actors involved and for their relationship.

Finally, this paper has used two illustrative case studies and built on the conceptual developments within the IMP Group. But the paper highlights the paucity of large- 
scale research on the nature of service provision and on the nature of value creation in business networks.

\section{REFERENCES}

Anderson, J. C. \& Narus, J.A. (1999). Business Market Management. Understanding, Creating, Delivering Value. London: Prentice-Hall.

Borden, N. (1964). The concept of the marketing mix. Journal of Advertising Research, June: 2-7.

Easton, G. (2010). Critical realism in case study research. Industrial Marketing Management, 39 (1), 118-128.

Ford, D. \& Håkansson, H. (2006a). IMP - Some Things Achieved: Much More to Do. European Journal of Marketing, 40 (3/4), 248 -258.

Ford, D. \& Håkansson, H. (2006b). The Idea of Interaction. IMP Journal, 1 (1), 4-27.

Ford, D. \& Mouzas, S. (2010). Networking under Uncertainty: Concepts and Research Agenda, Industrial Marketing Management, 39, 956-962.

Ford, D. \& Redwood, M. (2005). Making sense of network dynamics through network pictures: a longitudinal case study. Industrial Marketing Management, 34(7), 648-657.

Ford, D. (2011). IMP and Service Dominant Logic: Divergence, Convergence and Development, Industrial Marketing Management, 40, 231-239.

Ford, D., Gadde L-E, Håkansson, H. \& Snehota, I (2003). Managing Business Relationships, Second Edition, Chichester, John Wiley. 
Ford, D., Gadde, L-E, Håkansson, H. Snehota, I. \& Waluszewski, A. (2008). Analysing Business Interaction. 24 $4^{\text {th }}$ IMP Annual Conference, Uppsala, Sweden.

Gibbert, M., Ruigrock W. \& Wicki, B. (2008). What passes as a rigorous case study? Strategic Management Journal, 29(13), 1465-1474.

Gripsrud, G. (2004). The marketing discipline and distribution research: time to regain lost territory. In: Håkansson, H., Harrison, D. \& Waluszewski, A. (eds.) Rethinking Marketing. Developing a new understanding of markets. Chichester: Wiley.

Grönroos, K. (2008). Service logic revisited: who creates value? And who co-creates? European Business Review, 20 (4): 298 - 314.

Grönroos, K. (2011a). Value Co-creation in Service Logic: A Critical Analysis, Marketing Theory, 11(3), 279-301.

Grönroos, K. (2011b). “A Service Perspective on Business Relationships: The Value Creation, Interaction and Marketing Interface”, Industrial Marketing Management, 40, 240-247.

Halinen, A. \& Torrnroos, J. (2005). Using case methods in the study of contemporary business networks. Journal of Business Research, 58 (9), 1285-97.

Håkansson, H. \& Snehota I. (1995). Developing Relationships in Business Networks, London, Thomson International.

Håkansson, H. (1982) Industrial Marketing and Purchasing: An Interaction Approach, Chichester, John Wiley.

Håkansson, H. (1989). Corporate Technological Behaviour, London, Routledge.

Håkansson, H. Ford, D., Gadde, L-E., Snehota, I., \& Waluszewski, A. (2010). Business in Networks, John Wiley \& Sons. 
Håkansson, H., Ford, D., Gadde, L-E, Snehota, I. \& Waluszewski, A. (2009). Business in Networks, Chichester, John Wiley.

Håkansson, H., Johanson, J. \& Wootz, B. (1976). Influence Tactics in Buyer-Seller Processes, Industrial Marketing Management, 5, December, 319-332.

Henneberg, S., Mouzas, S. \& Naudé, P. (2006). Network Pictures: Concepts and Representations, European Journal of Marketing, 40 (3/4), 408-429.

Henneberg, S., Naudé \& Mouzas, S. (2010). Sense-Making and Management in Business Networks - Some Observations, Considerations, and a Research Agenda”, Industrial Marketing Management, (forthcoming).

Henneberg, S., Pardo, C., Mouzas, S. \& Naudé, P. (2009). Value dimensions and relationship postures in dyadic 'key relationship programmes'. Journal of Marketing Management, 25 (5-6). pp. 535-550.

Hughes, T.P. (1987). The evolution of Large Technical Systems. In Bijker, W., Hughes, T.P., \& Pinch, T.J (eds.) The Social Construction of Large Technological Systems. Cambridge, Mass.: MIT Press.

Leek, S. \& Mason, K. (2009). Network Pictures: Building a holistic representation of a dyadic business-to-business relationship. Industrial Marketing Management, 38, 599-607.

Leek, S. \& Mason, K. (2009). Network Pictures: Building an holistic representation of a dyadic business to business relationship. Industrial Marketing Management, 38, 599-607.

Lepak, D.P., Smith, K.G. \& Taylor, M.S. (2007). Value creation and value capture: A multilevel perspective. Academy of Management Review, 32 (1), 180-194.

Maskin, E., Tirole T. (1999). Unforeseen contingencies and incomplete contracts. The Review of Economic Studies, 66 (1), 83-114. 
McCarthy, E. J. (1960). Basic Marketing: A Managerial Approach. Homewood, IL: Richard D. Irwin.

Migram, S. (1967). The small-world problem, Psychology Today. 1 (1), 60-7.

Mnookin, R.H., Peppert, S.R., \& Trumello, A. 2000. Beyond winning: Negotiating to create value in deals and disputes. Cambridge, MA: Harvard University Press.

Mouzas, S. \& Araujo, L. (2000). Implementing Programmatic Initiatives in Manufacturer-Retailer Networks. Industrial Marketing Management. 29(4), 293-303.

Mouzas, S. \& Ford, D. (2009). The Constitution of Networks. Industrial Marketing Management, 38, 495-503.

Mouzas, S. \& Ford, D. (2012). Leveraging Knowledge Based Resources: The Role of Contracts. Journal of Business Research, 65 (2): 153-161.

Mouzas, S., \& Ford, D. (2006). Managing Relationships in Showery Weather: The Role of Umbrella Agreements. Journal of Business Research, 59:1248-1256.

Mouzas, S., Naudé, P. \& Henneberg, S. (2008). Developing Network Insight. Industrial Marketing Management, 37 (2), 166 -179.

Oberg, C., Henneberg, S.C., \& Mouzas, S. (2007). Changing network pictures: evidence from mergers and acquisitions. Industrial Marketing Management, 36 (7), 926-940.

Ragin, C. C., (1992). Casing and the Process of Social Inquiry. In Ragin, C.C, \& Becker, H.S. What is a Case? Exploring the Foundations of Social Inquiry. Cambridge University Press.

Sander, F., Peppet, S., \& Tulumello, A. (2000). Negotiating to create value in deals and disputes. Cambridge, MA: Harvard University Press. 
Tirole, J. (2009). Cognition and Incomplete Contracts. American Economic Review 99, 265-294.

Tsoukas, H. (1989). The Validity of Idiographic Research Explanations. Academy of Management Review, 14(4), 551-561.

Vargo, S.L. \& Lusch, R.F. (2011). It's all B2B .... and beyond: Toward a systems perspective of the market', Industrial Marketing Management (40), 181-187.

Vargo, S.L. \& Lusch, R.F. (2004). The four service marketing myths: remnants from a manufacturing model, Journal of service research, May, 324-335.

Vargo, S.L. \& Lusch, R.F. (2006). SDL: What it is, what it is not and what it might be. In Lusch R.F. \& Vargo, S.L. The SDL of marketing: Dialog, debate and direction, pp. 43-560, Armont, New York: ME Sharpe.

Vargo, S.L. \& Lusch, R.F. (2008). Service Dominant Logic: Continuing the evolution, Journal of the Academy of Marketing Science, 36, 1-10.

Villas-Boas, J.M. \& Zhao, Y. (2005). Retailers, manufacturers, and Individual Consumers: Modeling the supply side in the ketchup marketplace. Journal of Marketing Research, 42(1), 83-95.

Webster, F.E. (1965). The "Deal-Prone" Consumer. Journal of Marketing Research, 2 (2), 186-189.

Yin, R.K. (1994). Case Study Research and Methods, Newbury Park, California: Sage. 